\title{
Climate Sensitivity and the Value of Agricultural Production in the Brazilian Northeast: An Approach Using Spatial Panel Data
}

\author{
Helson Gomes De Souza ${ }^{1}$, Pablo Urano de Carvalho Castelar ${ }^{2}$, Edward Martins Costa ${ }^{3}$ \& Francisco José Silva \\ Tabosa $^{3}$ \\ ${ }^{1}$ Department of Economics, Federal University of Paraíba (UFPB), Brazil \\ ${ }^{2}$ Finance Course, Federal University of Ceará (UFC), Brazil \\ ${ }^{3}$ Agricultural Economics Department, Federal University of Ceará (UFC), Brazil \\ Correspondence: Pablo Urano de Carvalho Castelar, Professor, Finance Course, Federal University of Ceará (UFC), \\ Brazil.
}

Received: December 11, 2020

Accepted: January 20, $2021 \quad$ Online Published: September 17, 2021

doi:10.5430/ijba.v12n5p65

URL: https://doi.org/10.5430/ijba.v12n5p65

\begin{abstract}
This work analyzes the sensitivity of agricultural production in relation to changes in precipitation and temperature levels in the Northeast region of Brazil. For that purpose, data from 2006 to 2016 were used for 952 municipalities in the area. The econometric methodology derived from Kunwar and Bohara (2017) and is applied to the production value of municipalities in the Brazilian Northeast, where it is assumed that the production value is also impacted by the interactions between precipitation and temperature. Thus, time and space data are used, applied to a spatial econometric methodology. The results suggest that the agricultural production of the municipalities of the Brazilian Northeast is spatially autocorrelated. There is indication that there are municipalities with high (or low) levels of production, which have neighbors with these same characteristics. It was also verified that, from 2006 to 2011 , the agricultural production was more sensitive to changes in temperature levels than to changes in average precipitation. However, after the years 2012, 2013, 2015 and 2016, agricultural production has become more sensitive to changes in the precipitation levels. It was also noted that in the analyzed period there was an increase in the average sensitivity of the agricultural production in relation to the precipitation levels, while the average temperature sensitivity showed a decrease.
\end{abstract}

Keywords: climate change, agricultural sensitivity, agriculture, agricultural economics

\section{Introduction}

It is reasonable to assume that climate conditions affect economic outcomes. The geographic scenario in which a country or region is located, and changes which occur therein, will naturally lead to different results in terms of production. Therefore, how these changes in climate conditions impact production, and by how much, has been cause for analysis and concern in recent years.

The environmental impacts caused by climate change have been an issue that has gained relevance in the socioeconomic context since the late $20^{\text {th }}$ and the beginning of the 21 st century. In light of the recent effects of climate change on the environment and the global economy, tools have been put in place to mitigate the impacts of climate-related economic activities worldwide (Kunwar and Bohara, 2017).

Thus, nations have, in recent years, taken greater responsibility for the effects of climate change. For example, the formulation of global goals and international agreements aims at minimizing these effects. An example of this was the Paris Agreement, set up at the 21st Conference of Parties (COP21), in Paris, France. The agreement seeks to strengthen the global response to the threat of climate change and strengthen the capacity that countries have to deal with the impacts of climate change (Note 1).

Data from the National Aeronautics and Space Administration (Note 2) (NASA) show that the average global temperature has increased since the late nineteenth and early twentieth century, and that global temperature growth rates began to increase after the 1940s, and intensified after the 1970s. 
The academic literature on the subject, also, seems to indicate problematic consequences to climate change, particularly concerning its effects on agriculture in underdeveloped countries.

Yalew et al. (2017), for instance, using a microeconomic approach, find that changes in the climate cause different socioeconomic impacts, that can be intensified depending on the sector analyzed. However, the authors demonstrate that the sector that is most impacted by climate change is agriculture. As a result, these impacts are more intense on economies which are mainly focused on the primary sector.

Rosegrant et al. (2008) indicate that climate change will lead to future effects that will have major impacts, especially in economies based on the agricultural export sector. For the authors, underdeveloped countries located along and south of the Equator will be more affected. In this context, Rosegrant et al. (2008) forecast the influence of climate change and indicate a large future loss of production in Brazil, especially in relation to sugarcane, rice and soybean crops.

Machado Filho et al. (2016) highlight the effects of climate change in some specific regions of Brazil. The authors verified that the changes in the climate make it difficult to exit the poverty condition in rural areas in the North and Northeast regions of the country. In addition, the agricultural sector of the Northeast of Brazil suffers greater impacts from the changes in the climate behavior, especially when it comes to family and subsistence farming.

In this context, the Brazilian National Institute for Space Research (INPE, 2015) reports that the general trend indicates a reduction in the level of precipitation in the Northeast region of Brazil, as well as the temperature diverging in relation to its historical average in the region. For Machado Filho et al. (2016), the main consequences of this phenomenon are the loss of profitability of agriculture in the region and the intensification of poverty and social precariousness in the rural areas of the Northeast.

As discussed by Nunes (2016), the different regions of a country, particularly one of continental dimensions such as Brazil, suffer disparate effects because of climate change. In particular, says the author, the North and Northeast regions are the most vulnerable to the current shifts in the climate, because these regions are considered extremes in terms of environment. The author bases her statement on the Climate Report of the Ministry of the Environment, the Secretariat of Biodiversity and Forests and the Directorate of Biodiversity Conservation of 2015. Obermaier and Rosa (2013), likewise, also point out that the semi-arid regions, such as the Brazilian Northeast, tend to suffer a greater impact of the variations in the climate.

In view of these considerations, the present work aims to answer the question: What are the impacts of climate change on the agricultural production in the Northeast of Brazil? Therefore, the main objective of this research is to verify the sensitivity of the Brazilian Northeast agricultural production in relation to the changes in precipitation and temperature levels. The hypothesis is that the agricultural production of the Brazilian Northeast is spatially autocorrelated, generating the spatial overflow of the changes in the production of a certain region to the neighboring spaces, or municipalities.

The contribution intended concerns the quantification of the sensitivity that the agricultural sector has to climate change, in a region where the economy is highly dependent on agriculture.

The present work is subdivided into five sections, including this brief introduction. The second, which follows, encompasses the theoretical and literary foundation under which the work is based. The third refers to the methodological framework used. The fourth discusses the results found. Lastly, the concluding remarks are presented.

\section{Literature Review}

Climate change has had worrying effects in recent years, and these shifts have a stronger impact on the agricultural sector, as discussed by various authors. This section intends to highlight only a few of those contributions, in order to motivate the analysis performed.

In this sense, the economic literature has been giving significant prominence to works that analyze the behavior of agriculture in relation to climatic variations. Note, for example, Piao et al. (2010), Parry et al. (2004), Fischer et al. (2002), and Wiebe et al. (2015), all of which, on some level, find correlation between shifts in the climate and economic productivity.

According to the Food and Agriculture Organization of the United Nations (FAO, 2009), climate change has effects on the agricultural sector and affects other sectors through existing sectoral integrations. Changes in the levels of greenhouse gas emissions, temperature and precipitation cause direct changes in agricultural production, which generate impacts on the prices of primary extraction products, impacting, thus, other sectors. 
Parry et al. (2004) forecast global food production, taking into account the effect of climate change and the characteristics of population growth in the world in recent years. The authors conclude that the consequences of climate change can be catastrophic over the next 60 years. For these authors, it is necessary to implement long-term policies aimed at preventing the impacts suffered by the agricultural sector caused by climate change, such as reducing emissions of carbon dioxide (CO2) and other greenhouse gases.

In the view of Calzadilla et al. (2013), the greatest impact on the agricultural sector as a result of climate change is on the productivity of the factors of production. The authors analyze the potential impacts of climate change and $\mathrm{CO} 2$ fertilization on global agriculture, using a version of the GTAP-W model, which distinguishes between rainfed and irrigated agriculture and implements water as an explicit factor of production for irrigated agriculture, and predict results for agricultural production through projections up to the year 2050, taking into account the effects of climate change on the level of production of agriculture and the well-being of individuals. Calzadilla et al. (2013) conclude that if the behavior of climate variables continues at the current pace, agricultural production and welfare will fall worldwide in the next three decades.

Using a different methodological approach, Evangelista et al. (2013) determine that the analyses of the impact of changes in the climatic variables on the agricultural sector should take the spatial factor into account. The authors consider the modifications in the levels of precipitation and temperature and their impacts on the agricultural production in Ethiopia, where nearly all of the country's agriculture is dependent on rainfall. Evangelista et al. (2013) verify, then, using a Maxent software fit with crop data collected from household surveys and bioclimatic variables from the WorldClim database to develop spatially explicit models of crop production in Ethiopia, that these changes exhibit a common spatial behavior during the year. In addition, the authors determine that the impacts of climate change on agriculture are spatially concentrated in some periods and subsequently spread throughout the area under analysis.

For Ju et al. (2013), the changes in the temperature levels of the last decades have caused considerable impacts on world agricultural production, which requires the development of adaptation methods to these changes. However, the authors indicate that hydric soil changes resulting from the alteration of rainfall levels have a greater impact on the agricultural sector. This result is also verified by Kunwar and Bohara (2017), where the authors observe that the values of rural properties show sensitivity to the changes of precipitation superior to the sensitivity of the changes in the temperature.

The approach developed by Ochieng and Kirimi (2016), who estimate the effects of climate variability and change on agricultural revenues of small-scale farmers in Kenya, also indicates that agricultural production can be impacted by changes in temperature and precipitation levels. The authors, using a balanced panel household data set collected in 2000, 2004, 2007 and 2010, from eight agro-regional zones and climate data from 1980 to 2010, argue that the interactions between these two variables directly affect the behavior of agriculture. In addition, the authors indicate an increase in agricultural production elasticities related to the precipitation and temperature levels in a projection for the next three decades.

Ortiz-Bobea, Knippenberg and Chambers (2018) question whether ongoing transformations of the agricultural sector affect its ability to cope with climatic variations, specifically focusing on the United States of America, in the period of 1960-2004. The authors combine state-level measures of agricultural productivity with detailed climate data. The results suggest that agriculture is growing more sensitive to climate in Midwestern states of the US for two distinct but compounding reasons: a rising climatic sensitivity of nonirrigated cereal and oilseed crops and a growing specialization in crop production. In contrast, other regions specialize in less climate-sensitive production such as irrigated specialty crops or livestock. Thus, the authors conclude that reducing vulnerability to climate change should consider the role of policies in inducing regional specialization.

Schleussner et al. (2018) also discuss the issue of climate change and agricultural productivity. The authors assess changes in crop productivity under $1.5{ }^{\circ} \mathrm{C}$ and $2{ }^{\circ} \mathrm{C}$ warmer climates provided by the model intercomparison project 'Half a degree Additional warming, Prognosis and Projected Impacts' (or HAPPI). The analysis is based on modelled crop yield data from six models of the Global Gridded Crop Mode Intercomparison, which features data from 31 registered modeling groups from around the world, mainly Europe and North America. The work provides projections for the four major staple crops: wheat, maize, rice and soybean. Crop yield responses for varying $\mathrm{CO} 2$ concentrations are analyzed, which allows to disentangle the effect of $\mathrm{CO} 2$ fertilization and $0.5{ }^{\circ} \mathrm{C}$ warming increments. Also, the authors assess changes in 10-year minimum productivity to understand implications for yield stability. 
The results find consistent negative imprints of $0.5{ }^{\circ} \mathrm{C}$ warming increments for median as well as low productivity extremes alike for global food productivity with tropical regions being affected more strongly. Despite uncertainties in potential positive effects of elevated $\mathrm{CO} 2$ concentrations for crop productivity, the authors find that warming levels alone are insufficient to assess future impacts of climate change on future crop productivity. Furthermore, the findings indicate that impacts of warming on crop production will be consistently lower at $1.5{ }^{\circ} \mathrm{C}$ compared to $2{ }^{\circ} \mathrm{C}$. However, the authors warn of uncertainties related to potentially positive effects of increasing $\mathrm{CO} 2$ fertilization on crop productivity are found to dominate over warming increments.

In a more recent work, Dayaratna, McKitrick and Michaels (2020) focus on agricultural productivity and climate sensitivity and explore the implications of recent empirical findings about $\mathrm{CO} 2$ fertilization and climate sensitivity on the social cost of carbon (SCC) in the FUND model. New compilations of satellite and experimental evidence suggest larger agricultural productivity gains due to $\mathrm{CO} 2$ growth are being experienced than are reflected in FUND (Framework for Uncertainty, Negotiation and Distribution) parameterization. The authors argue that there is overwhelming evidence that $\mathrm{CO} 2$ increases have a beneficial effect on plant growth, so models that fail to take these benefits into account overstate the social cost of carbon. They also argue that the evidence on global greening and the response of agricultural crops to enhanced $\mathrm{CO} 2$ availability suggests that the productivity boost is likely stronger than that parameterized in FUND.

Oo et al. (2020) measure the economic impact of climate change on crop production in Myanmar, through a Ricardian approach. A cross-sectional survey covering three regions in the central dry zone: (Magwe, Mandalay, and Sagaing regions) was conducted, yielding a sample of 425 farmers. The authors find a non-linear relationship between climate indicators (temperature and precipitation) and revenue of land. Furthermore, marginal effects were calculated by selecting economic and socio-demographic variables, and he estimated marginal impacts suggest that the projected changes in temperature will affect the crop productivity of the region.

Shi et al. (2020) use the super undesirable dynamic Slacks-Based Measures (SBM) under an exogenous variable model to simulate the external environmental factors by adding extreme weather days. The intention is to analyze climate change impacts on agricultural production in China. The results show that the agricultural production efficiency is higher in the eastern region, and the difference in agricultural production efficiency among the provinces in the middle and western regions the country is large, showing a trend of polarization. The difference in the Gini coefficient between the middle and western regions is more significant. According to the authors, the regional concentration degree of agriculture in China is decreasing, the regional distribution of agricultural water resources is more balanced, and the national regional difference gradually decreases.

Performing a literary survey on climate issues in Brazil, Moraes and Ferreira Filho (2013) point out that it is necessary to understand the knowledge points concerning the issue of climate change in Brazil, at least in its economic aspects. Furthermore, the authors argue that only from having such knowledge it is possible to think about strategies, being this main contribution of the works in the area. Also, they emphasize that, in Brazil, mitigation policies are superior, in economic terms, to the perspectives of vulnerability and/or adaptation to climate issues. However, in their opinion, more consistent information is still necessary for society to plan its lines of action.

Cunha et al. (2013) emphasize that climate change in Brazil affects mainly small producers. Using a treatment effect model with propensity score matching, the authors argue that rainfed family agriculture is the most affected by these phenomena, thus this type of production has a high sensitivity with regard to changes in precipitation levels. Therefore, the authors stress that it is necessary to implement measures that facilitate the technological adaptation of small rural producers to climate variability in Brazil. Also, Cunha et al. (2013) cite irrigation as an adaptive measure to balance the effects of climate change on agriculture and highlight the importance of policies to support the expansion of this technique for small farmers.

For Obermaier and Rosa (2013), semi-arid regions are considered highly susceptible to the adverse impacts of climate change. In this context, the authors highlight the vulnerability of agricultural production in a large area considered as being semi-arid in Brazil, which extends from the north of the Brazilian states of Minas Gerais and Espirito Santo and extends over the vast majority of the territory of the Northeast region of the country.

Considering that a large part of family farming is already heavily impacted in the context of current climate variability, Obermaier and Rosa (2013) indicate that this implies that actions that reduce their vulnerability do not necessarily depend on the certainty of future climate impacts. Thus, measures that attempt to reduce existing socio-economic and environmental vulnerabilities may be more useful in making family farming in the Northeast of Brazil more resilient to anticipated changes. This work, however, is strictly a critical analysis of legislation, and not a quantitative study. 
In this sense, Araújo et al. (2014) analyze the effect of climate change on the agricultural productivity levels of the states of Northeast Brazil, considering the impact of temperature and precipitation levels on the productivity of crops such as maize, sugar cane and manioc. The authors, using a tobit model for panel data, conclude that the productivity levels of the crops studied could be much higher than those that would be observable if there were no changes in the climate. In addition, states such as Rio Grande do Norte, Paraíba and Pernambuco may show productivity losses in the three analyzed crops, both in the medium and long run. The authors also suggest that climate change will negatively impact productivity levels in the municipalities of the South and Center-South of the state of Bahia.

From another perspective, Domingues et al. (2011), analyze the impact of climate change in the Brazilian Northeast from estimates of the implications on the availability of suitable land for agricultural activity in a set of crops. The authors, using computable general equilibrium models, conclude that climate change increases the potential for economic losses in the Northeast region of the country, especially in the poorest states, pointing to the need for mitigation and emission control policies. These authors further indicate that, if measures to prevent and lessen the effects of climate change are not implemented, the economic effects on employment, for example, could have a significant impact on migratory flows, impacting the high pressure on urban infrastructure of the various metropoles of the Northeast and other regions of the country.

According to the work developed by Machado Filho et al. (2016). agriculture in the Brazilian Northeast presents a high vulnerability to the changes in the climate, mainly in what concerns shifts in pluviometry. The authors point out that in the coming years, the effects of climate change on agriculture in the Northeast of Brazil will be intensified in a higher proportion than the other regions, and hydric changes are the main issues responsible for the problem. The authors also point out that family farming in the Northeastern region will suffer greater impacts from climate change than other subsectors, thus arguing for the need to implement policies aimed at controlling and supplying water to the region.

\section{Methodology}

\subsection{Initial Specification}

While analyzing the impact of climate change on agriculture, Kunwar and Bohara (2017) assume that the value of agricultural land is impacted by variations in rainfall and local temperature. Thus, the authors use a spatial methodology for panel data to measure the impact of climate change on the value of rural properties. Considering a Ricardian approach, Kunwar and Bohara (2017) assume that the value of rural properties is a function of the value of the average precipitation, average temperature, the deviations in precipitation and temperature, and the squared values of those variables.

In the present work, the approach used by Kunwar and Bohara (2017) is applied to the production value of municipalities in the Brazilian Northeast. However, it is assumed here that the production value is also impacted by the interactions between precipitation and temperature. In this sense, time and space data are used, applied to a spatial econometric methodology. The following subsections are intended to present the tools used for this procedure.

\subsection{Data}

The data used here comes from two different sources. In relation to the value of agricultural production, the sum of the total value of the production of temporary and permanent crops is reported in the Municipal Agricultural Production (Produção Agrícola Municipal - PAM), which is made available annually by the Brazilian Institute of Geography and Statistics (IBGE) in the IBGE System of Automatic Recovery (SIDRA). The value of production was corrected for December 2016 values by the Brazilian Extended Consumer Price Index (IPCA).

Regarding the climate variables, the information was obtained in the Agrometeorological Monitoring System (Agritempo). The mean temperature and precipitation were constructed using the arithmetic mean of the maximum and minimum daily estimates for each variable.

For the construction of the climate variables by seasons, the arithmetic mean of the daily mean values of precipitation and temperature was used. Following the specifications of INPE, the period between December 21 and March 19 was considered as summer; March 20 to June 20 as autumn; June 21 to September 21 as winter and September 22 to December 20 as spring (Note 3).

After the homogenization of the data, a total of 952 municipalities (Note 4) of the Brazilian Northeast region comprise the database, being 30 municipalities of the state of Sergipe, 37 municipalities in the state of Alagoas, 290 in the state of Bahia, 83 in the state of Pernambuco, 67 in the state of Paraíba, 55 in the state of Rio Grande do Norte, 
112 in Ceará, 338 in Piauí, and 140 in the state of Maranhão, Thus, the QGIS software was used to construct a digital layer in the shapefile format using points for the delimitation of the geographic location of each municipality, and afterwards, the Geoda software was used for the construction of the spatial weights matrices and calculation of the spatial autocorrelation indicators.

The period between 2006 and 2016 was chosen for this work. This choice was due to the greater availability of information on the climate variables featured in the Agritempo system.

\subsection{Stationarity Test for Panel Data}

The issue of non-stationarity or unit root is a characteristic of data which have its distributions contained in periods of time. According to Bueno (2008), stationarity occurs when a series fluctuates around a fixed average and if the variance of this series is constant over time. Bueno (2008) also points out that observing stationarity is fundamental to allow statistical inferences to be made on the parameters estimated based on a stochastic process. In this sense, before carrying out any statistical procedure, it is necessary to verify the condition of stationarity. This procedure can be performed by means of an autoregressive process below:

$$
Y_{t}=\rho Y_{t-1}+u_{t}
$$

Where $u_{t}$ is the stochastic error term, called white noise, if it its mean is zero, the variance is constant and it is not autocorrelated. Thus, in a situation where $\rho=1$, there will be a unit root problem. In order to detect this characteristic, the present work makes use of the Levin-Lin-Chu stationarity test so that, if the null hypothesis of the test is rejected, the data used are stationary.

\subsection{Spatial Proximity Matrix}

As the present work uses data distributed in time and space, the first step to be considered is to model the proximity of the spatial units in a numerical way. For this purpose, a spatial proximity matrix is constructed, consisting of an instrument capable of identifying neighboring units of a given region by means of the representation of areas in numerical terms. Based on the specification given by Almeida (2012), the neighborhood matrix has the following structure:

$$
W_{i j}=\left\{\begin{array}{l}
1 \text { if } i \text { and } j \text { are neighbors } \\
0 \text { if } i \text { and } j \text { are not neighbors }
\end{array}\right.
$$

\subsection{Global Spatial Autocorrelation}

When dealing with spatial data, before performing any econometric procedure, it is necessary to make an analysis of the characteristics of the spatial distribution of the data. This analysis is done in the present work through the verification of spatial autocorrelation, using the Moran Global Index, presented by Anselin (1994). as:

$$
I=\frac{\sum_{i} \sum_{j} W_{i j}\left(Z_{i}-\bar{Z}\right)\left(Z_{j}-\bar{Z}\right)}{\sum_{i}^{n}\left(Z_{i}-\bar{Z}\right)^{2}}
$$

Where $n$ represents the number of regions analyzed, $Z_{i}$ is the value of the analyzed variable in area $I, \bar{Z}$ is the mean value of the variable in a certain area, and $W_{i j}$ represents the values indicated by the spatial proximity matrix used. The rejection of the null hypothesis of Moran's I, together with the positive sign, indicates the presence of spatial autocorrelation in the data. Non-rejection of the null hypothesis or the negative sign indicates a random dispersion of the data.

\subsection{Econometric Methodology}

In order to verify the sensitivity of agricultural production to climate change, the present work makes use of the method proposed by Kunwar and Bohara (2017), which uses a Ricardian approach to measure the sensitivity of the value of rural establishments to climate change in Nepal.

Initially, a conventional model for panel data is considered, which is given by:

$$
\begin{aligned}
& y_{i t}=\alpha_{i}+\beta \text { Cmed }_{i t}+\theta \text { Cmed }_{i t}^{2}+\vartheta \operatorname{Cestdv}_{i t}+\sigma \text { Cest }_{i t}^{2}+\omega(\text { prec } * \text { temp })+ \\
& \Gamma(\text { prec } * \text { temp })^{2}+\Phi(\text { Control })+\varepsilon_{t}
\end{aligned}
$$

Where $\left\{\alpha_{1} \ldots . \alpha_{n}\right\}$ is a vector corresponding to the fixed effects? $y$ is the natural logarithm of the value of agricultural production, $\mathrm{Cmed}_{i t}$ is the annual mean of the climate variable (temperature and precipitation) (Note 5), Cestdv $v_{i t}$ represents the deviations of the climatic variables by season of the year, prec represents the precipitation, temp is the temperature and $\varepsilon_{t}$ is the random error. 
However, Anselin (1990) indicates that when dealing with spatial data, the assumption of homogeneity must be addressed in the econometric procedures used. Non-homogeneity may indicate that the coefficient of an explanatory variable is statistically significant in a given municipality and not significant in another spatial unit.

Some techniques for crossection estimations are able to control this problem. However, these operations may not produce the same effects for stacked data. Thus, Elhorst (2003) indicates that the combination of stacked data with spatial models is one of the most robust tools in the field of spatial econometrics and that there are still unanswered questions about these methods, such as the control of spatial heterogeneity over the estimated coefficients.

Barreto et al. (2010) use fixed effects to control spatial heterogeneity, a procedure also adopted in the present investigation. Still, Baylis et al. (2011) emphasize that in this type of approach, one must also reduce errors by including factors external to the climatic variables that affect agriculture in the different units of space such as population, infrastructure, income, demographic density, conditioning factors irrigation etc. Therefore, the reduction of the effects from stochastic errors can be achieved by inserting a set of control variables into the estimates (Note 6).

In the present work, control variables were incorporated in view of data availability and taking into account the procedures used in literature as done by Baylis et al. (2011) and Kunwar and Bohara (2017). With this, the natural logarithm of the Municipal Gross Domestic Product (GDP) (Note 7). the average area available per inhabitant (Note 8 ) and the natural logarithm of the municipal population (Note 9).

Starting from Equation 4 and using the procedure of incorporation of the spatial effects given by Elhorst (2010), one arrives at a general fixed effects model that includes the spatial dependency including spatial lags to have control of the spatial autocorrelation, being given by:

$$
\begin{aligned}
& y_{i t}=\alpha+\rho W_{1} y_{i t}+\beta \text { Cmed }_{i t}+\theta \text { Cmed }_{i t}^{2}+\vartheta \text { Cestd }_{i t}+\sigma \text { Cest }_{i t}^{2}+\omega(\text { prec } * \text { temp })+\mathbb{\Gamma}(\text { prec } * \text { temp })^{2}+ \\
& \Phi(\text { Controle })+W_{1}\left(\text { Cmed }_{i t}+\text { Cmed }_{i t}^{2}+\text { Cestdv }_{i t}+\text { Cest }_{i t}^{2}+\text { prec } * \text { temp }+(\text { prec } * \text { temp })^{2} \Phi(\text { Control })\right) \tau+ \\
& +\xi_{t}(5)
\end{aligned}
$$

With

$$
\xi_{t}=\lambda W_{2} \xi_{t}+\varepsilon_{t}
$$

Where $W_{1} y_{t}$ is the dependent variable spatially lagged, $W_{2} \xi_{t}$ are the error terms spatially lagged, $W$ is the neighborhood matrix, and $\lambda$ and $\rho$ are the scalar spatial parameters, being $\tau$ a vector of spatial coefficients.

The general model of random effects with spatial dependence is presented by Almeida (2012) as:

$$
\begin{aligned}
& \rho W y_{i t}+\beta \text { Cmed }_{i t}+\theta \text { Cmed }_{i t}^{2}+\vartheta \operatorname{Cestdv}_{i t}+\sigma \operatorname{Cest}_{i t}^{2}+\omega(\text { prec } * \text { temp })+\mathbb{\Gamma}(\text { prec } * \text { temp })^{2}+\emptyset(\text { Controle })+ \\
& W\left(\text { Cmed }_{i t}+\text { Cmed }_{i t}^{2}+\text { Cestdv }_{i t}+\text { Cest }_{i t}^{2}+\text { prec } * \text { temp }+(\text { prec } * \text { temp })^{2}+\Phi(\text { Control })\right) \tau+\xi_{t}
\end{aligned}
$$

With

$$
\xi_{t}=\alpha+\lambda W \xi_{t}+\varepsilon_{t}
$$

Imposing the restriction $\rho \neq 0, \tau=0$ and $\lambda=0$ to the model specified in Equation (5), one obtains the fixed effects model with spatial lags given by:

$$
\begin{aligned}
y_{i t}= & \alpha+\rho y_{i t}+\beta \text { Cmed }_{i t}+\theta \text { Cmed }_{i t}^{2}+\vartheta \text { Cestd }_{i t}+\sigma \text { Cest }_{i t}^{2}+\omega(\text { prec } * \text { temp })+\mathbb{T}(\text { prec } * \text { temp })^{2}+ \\
& \Phi(\text { Controle })+\varepsilon_{t}
\end{aligned}
$$

Imposing the restriction $\rho \neq 0, \tau=0$ and $\lambda=0$ to the model specified in Equation (6), one obtains the random effects model with spatial lags given by:

$$
\begin{aligned}
y_{i t}= & \rho W y_{i t}+\beta \text { Cmed }_{i t}+\theta \text { Cmed }_{i t}^{2}+\vartheta \text { Cestd }_{i t}+\sigma \text { Cest }_{i t}^{2}+\omega(\text { prec } * \text { temp })+ \\
& \mathbb{\Gamma}(\text { prec } * \text { temp })^{2}+\Phi\left({\text { Control })+\xi_{t}}^{2}\right.
\end{aligned}
$$

With

$$
\xi_{t}=\alpha+\varepsilon_{t}
$$

The spatial error model with fixed effects is also considered, which is characterized by featuring the spatial autocorrelation in the form of an autoregressive error. In order to obtain this model, the constraints $\rho=0, \tau=0$ and $\lambda \neq 0$ are imposed on Equation (5), to achieve:

$$
\begin{aligned}
y_{t}= & \alpha+\beta \text { Cmed }_{i t}+\theta \text { Cmed }_{i t}^{2}+\vartheta \text { Cestd }_{i t}+\sigma \text { Cest }_{i t}^{2}+\omega(\text { prec } * \text { temp })+\mathbb{\Gamma}\left({\text { prec } * \text { temp })^{2}+}^{2}\right. \\
& \Phi(\text { Control })+\xi_{t}
\end{aligned}
$$


With

$$
\xi_{t}=\lambda W \xi_{t}+\varepsilon_{t}
$$

For the spatial error model with random effects, the constraints $\rho=0, \tau=0$ e $\lambda \neq 0$ in Equation (6) yield:

$$
\begin{aligned}
y_{t}= & \beta \text { Cmed }_{i t}+\theta \text { Cmed }_{i t}^{2}+\vartheta \text { Cestd }_{i t}+\sigma \text { Cest }_{i t}^{2}+\omega(\text { prec } * \text { temp })+\mathbb{T}(\text { prec } * \text { temp })^{2}+ \\
& \Phi(\text { Control })+\xi_{t}
\end{aligned}
$$

With

$$
\xi_{t}=\alpha+\lambda W \xi_{t}+\varepsilon_{t}
$$

The choice of the more appropriate model among the estimates is made using the criteria indicated by Almeida (2012, p.431), where the choice of the appropriate model should be made according to: (i) verifying if the observed effects should be included in the estimates; (ii) choosing the most appropriate model with unobserved effects; (iii) the appropriate model with no observed effects is estimated; (iv) checking the spatial dependence of the residue; (v) verifying the presence of spatial autocorrelation in the residues of the model with unobserved effects, one estimates the panel data model encompassing spatial autocorrelation; (vi) the model that does not present spatial autocorrelation in the residues and that presents the least information criterion is chosen.

If the model chosen is the spatial lag model, as shown in Equation (7), it is possible to obtain the local and total impacts of the climate variations by calculating the marginal effects, which are given by LeSage and Pace (2009) as:

$$
\frac{\partial y_{i}}{\partial x_{i r}}=S_{r}(W)_{i i} \quad \text { and } \quad \frac{\partial y_{i}}{\partial x_{j r}}=S_{r}(W)_{i j}
$$

In which $S_{r}(W)=\left(I_{n}-\emptyset W\right)^{-1} \beta_{r}, i$ and $j$ represent municipalities $i$ and $j$ respectively. $\beta_{r}$ is the coefficient of the $r$-th variable and $S_{r}(W)$ is an $n \times n$ matrix where the elements contained in the main diagonal represent the direct impacts and the elements outside the main diagonal represent the indirect impacts. The sum of these two impacts forms the total impact. Once the estimates have been made and the appropriate model chosen, the next step is to calculate the sensitivity of the agricultural production in relation to the level of precipitation and the temperature. Following the procedure of Kunwar and Bohara (2017), and including the interactions between precipitation and temperature, this process is given by:

$$
E\left(\frac{\partial \ln (y)}{\partial p r e c}\right)=\beta+2 * \theta * \text { prec }+\omega * \text { temp }+2 * \mathbb{\Gamma} * \text { prec } * \text { temp } p^{2}
$$

and

$$
E\left(\frac{\partial \ln (y)}{\partial t e m p}\right)=\beta+2 * \theta * \text { temp }+\omega * \operatorname{prec}+2 * \mathbb{\Gamma} * \operatorname{prec}^{2} * \text { temp }
$$

\section{Results}

To specify the characteristics of the data used, Table 1 shows the descriptive statistics of the variables. Mean precipitation and mean temperature was obtained by the ratio of the sum of the values and the number of days of the period (Note 10). The average precipitation of the analyzed period was $2.7175 \mathrm{~mm}$. which, in accumulated values, would generate an average annual precipitation of approximately $990 \mathrm{~mm}$. It is also observed that the greatest precipitations occur during the summer and fall, which corresponds to the period from December 21 to June 20.

The average temperature for the analyzed period was $25.7391^{\circ} \mathrm{C}$. Checking the square of the averages by seasons, it is observed that the highest temperatures occur in the spring, that is, between September 22 and December 20.

The standard deviations (Note 11) inform how much the climate variables distance themselves from the average, allowing an approximation of the quantification of the climate changes. Regarding precipitation and temperature, Table 1 shows that, on average, the greatest climate changes occur during the winter, that is, between June 21 to September 21. 
Table 1. Descriptive statistics of the variables

\begin{tabular}{|c|c|c|c|}
\hline Variable & Observations & Mean & Standard Deviation \\
\hline Ln(Production) & 10.472 & 8.5658 & 1.8538 \\
\hline Precipitation & 10.472 & 2.7175 & 1.7194 \\
\hline Temperature & 10.472 & 25.7391 & 1.7194 \\
\hline Precipitation $^{2}$ & 10.472 & 10.3410 & 24.0820 \\
\hline Temperature $^{2}$ & 10.472 & 669.5832 & 128.0241 \\
\hline prec $*$ temp & 10.472 & 69.5731 & 40.8843 \\
\hline$(\text { prec } * \text { temp })^{2}$ & 10.472 & 6511.7760 & 9036.4000 \\
\hline Prec_spring $^{2}$ & 10.472 & 7.2106 & 24.8750 \\
\hline Prec_summer ${ }^{2}$ & 10.472 & 27.3372 & 40.5980 \\
\hline Prec_autumn $^{2}$ & 10.472 & 29.4538 & 51.0579 \\
\hline Prec_winter $^{2}$ & 10.472 & 1.9986 & 21.9598 \\
\hline Temp_spring ${ }^{2}$ & 10.472 & 728.3846 & 136.2860 \\
\hline Temp_summer ${ }^{2}$ & 10.472 & 711.5912 & 111.5421 \\
\hline Temp_autumn ${ }^{2}$ & 10.472 & 646.8529 & 129.8654 \\
\hline Temp_winter ${ }^{2}$ & 10.472 & 599.9043 & 155.3370 \\
\hline Temp_spring_dv & 10.472 & 1.1144 & 0.8214 \\
\hline Temp_summer_dv & 10.472 & 0.8417 & 1.1459 \\
\hline Temp_autumn_dv & 10.472 & -0.4642 & 0.7455 \\
\hline Temp_winter_dv & 10.472 & -1.4836 & 1.1371 \\
\hline Prec_spring_dv & 10.472 & -0.8449 & 1.9794 \\
\hline Prec_summer_dv & 10.472 & 1.5985 & 1.7991 \\
\hline Prec_autumn_dv & 10.472 & 1.4435 & 2.2507 \\
\hline Prec_winter_dv & 10.472 & -2.1353 & 1.5046 \\
\hline \multicolumn{4}{|l|}{ Control } \\
\hline Area/Population & 10.472 & 0.0785 & 0.1192 \\
\hline LnGDP_percapita & 10.472 & 8.9505 & 0.5953 \\
\hline Lnpopulation & 10.472 & 9.7994 & 0.9722 \\
\hline
\end{tabular}

Source: Prepared by the authors based on estimations from Agritempo (2017).

Note: $\operatorname{Prec}=$ precipitation $(\mathrm{mm}) ;$ temp $=$ temperature $\left({ }^{\circ} \mathrm{c}\right) ; d v=$ standard deviation.

Before making any statistical inference, it is necessary to verify the temporal characteristics of the data. Therefore, the stationarity condition of the variables was analyzed by the Levin-Lin-Chu stationarity test. The results of this procedure are shown in Table 9, featured in the appendix. The rejection of the null hypothesis confirms that all the variables used are distributed around a fixed mean, with constant variance over time, which indicates the stationarity condition of the series.

Table 2 presents the results obtained with the Moran Global Index for the agricultural production of the analyzed municipalities. For all the years considered in the sample, the Moran Global Index presented a positive value and was statistically significant. This result indicates that the agricultural production of the studied municipalities is spatially autocorrelated. This implies a spatial overflow of production, that is, changes occurred in the agricultural 
production of a given municipality overflow in spatial terms, causing changes in the agricultural production of the neighboring municipalities.

Table 2. Global spatial autocorrelation of the value of agricultural production

\begin{tabular}{lll}
\hline & Moran's I & P - Value \\
\hline 2006 & 0.477 & 0.0001 \\
\hline 2007 & 0.513 & 0.0001 \\
\hline 2008 & 0.498 & 0.0000 \\
\hline 2009 & 0.482 & 0.0010 \\
\hline 2010 & 0.555 & 0.0000 \\
\hline 2011 & 0.494 & 0.0002 \\
\hline 2012 & 0.474 & 0.0000 \\
\hline 2013 & 0.524 & 0.0003 \\
\hline 2014 & 0.506 & 0.0000 \\
\hline 2015 & 0.522 & 0.0001 \\
\hline 2016 & 0.458 & 0.0000 \\
\hline
\end{tabular}

Source: Prepared by the authors.

Note: The statistical significance considered for this work is the $5 \%$ level.

After verifying the presence of spatial autocorrelation in the data used, the next step is to measure the sensitivity of agricultural production in relation to precipitation and temperature by means of a procedure that encompasses the effects stemming from these phenomena. In the present work this process is done through a spatial data panel. In order to decide which estimator should be considered, an F test was initially used to verify the possibility of estimation of the models through Ordinary Least Squares via a pooled model. With this procedure, the null hypothesis of there being no significant effects was rejected. In addition, a Breusch-Pagan test was performed and it was verified that it is not possible to ignore the presence of significant effects, which can only be adequately treated through the Fixed Effects estimator.

Once the estimates are obtained, one must check whether the effects should be treated as fixed or random. For that purpose, the Hausman test is used in this work. It is verified that in all the estimations the random effects are invalid, and, therefore, the fixed effects model must be considered to answer the problem here. The results of these procedures are presented in Table 3.

For models with spatial specification, a neighborhood matrix of type $K$ neighbors with $\mathrm{K}=1$ was used. The choice of this matrix was determined by the criteria indicated by Baumont (2004). This mechanism consists in estimating the model without the spatial effects, obtaining the model residues and verifying the spatial autocorrelation of the residues through the Moran Global Index, taking into account a set of neighborhood matrices (Note 12). Then, the matrix chosen will be the one that obtains the greatest statistically significant value for the Moran Global Index applied to the residuals of the model without spatial effects.

In order to choose the model that explains the problem in question more adequately, the procedure indicated by Almeida (2012. p.431) was used. as specified in subsection 3.4. Having fulfilled the prepositions (i), (ii), (iii), (iv) and (v), the absence of spatial autocorrelation in the spatial specification of the fixed effects models was verified. Thus, the appropriate model that explains the relationships analyzed is the spatial lag model, considering that it presented the lowest information criterion.

Analyzing the spatial lag model, it is verified that the spatial autocorrelation coefficient $(\rho)$ features a positive signal and was statistically significant. This result may indicate the existence of clusters for agricultural production in the Northeast region of Brazil. Furthermore, the value obtained with the coefficient $(\rho)$ indicates that the changes in the production of a given municipality overflow in spatial terms, also impacting neighboring municipalities. As a consequence of this result, it should be pointed out that a public policy aimed at impacting the agricultural 
production of the Northeast of Brazil should take into consideration the possibility of capturing the effects arising from spatial proximity.

The squares of the levels of precipitation by season show that increased precipitation in autumn reduces the value of agricultural production in the Brazilian Northeast. The values obtained with the coefficients of the temperatures per season of the year in their quadratic form indicate that temperature increases in autumn reduce agricultural production, while the increase in winter temperatures leads to greater values of agricultural production in the Northeast.

The results obtained with the temperature deviations show that the increase in the positive distance between the temperature in autumn and the average annual temperature causes increases in the value of agricultural production in the Northeast. In relation to precipitation deviations, it is observed that the increase in the positive distance between spring precipitation and the annual average precipitation reduces the production value in the region.

Regarding the control variables, the results show that the increase of the available area for each inhabitant as well as for the municipal population in general reduces the value of agricultural production.

Table 3. Estimation results using fixed effects

\begin{tabular}{|c|c|c|c|}
\hline & Normal & Lag & Error \\
\hline Constant & $8.3041^{*}$ & - & - \\
\hline$\rho$ & - & $0.2231^{*}$ & - \\
\hline$\lambda$ & - & - & $0.2137 *$ \\
\hline Prec & $-0.7214^{*}$ & $-0.5836^{*}$ & $-0.6375^{*}$ \\
\hline Temp & $0.1829 *$ & $0.1506^{*}$ & 0.1422 \\
\hline Precipitation $^{2}$ & $0.0253^{*}$ & $0.0202 *$ & $0.0209^{*}$ \\
\hline Temperature ${ }^{2}$ & 0.0037 & 0.0029 & 0.0043 \\
\hline prec $*$ temp & $0.0411 *$ & $0.0332 *$ & $0.0366^{*}$ \\
\hline$(\text { prec } * \text { temp })^{2}$ & $-0.0001^{*}$ & $-0.0001^{*}$ & $-0.0001 *$ \\
\hline Prec_spring ${ }^{2}$ & -0.0010 & -0.0007 & 0.0005 \\
\hline Prec_summer $^{2}$ & -0.0011 & -0.0007 & -0.0009 \\
\hline Prec_autumn ${ }^{2}$ & $-0.0025^{*}$ & $-0.0018^{*}$ & $-0.0024 *$ \\
\hline Prec_winter $^{2}$ & -0.0008 & -0.0006 & -0.0007 \\
\hline Temp_winter ${ }^{2}$ & -0.0003 & -0.0007 & -0.0008 \\
\hline Temp_summer ${ }^{2}$ & -0.0016 & -0.0014 & -0.0014 \\
\hline Temp_autumn ${ }^{2}$ & $-0.0111^{*}$ & $-0.0086^{*}$ & $-0.0104 *$ \\
\hline Temp_winter ${ }^{2}$ & $0.0030^{*}$ & $0.0026^{*}$ & $0.0029 *$ \\
\hline Temp_spring_dv & 0.0627 & 0.0687 & 0.0953 \\
\hline Temp_summer_dv & 0.0682 & 0.0569 & 0.0658 \\
\hline Temp_autumn_dv & $0.4266^{*}$ & $0.3305^{*}$ & $0.4025^{*}$ \\
\hline Temp_winter_dv & -0.0998 & -0.0863 & -0.0906 \\
\hline Prec_spring_dv & $-0.0327^{*}$ & $-0.0258^{*}$ & $-0.0375^{*}$ \\
\hline Prec_summer_dv & 0.0224 & 0.0158 & 0.0205 \\
\hline Prec_autumn_dv & 0.0281 & 0.0209 & $0.0328^{*}$ \\
\hline Prec_winter_dv & -0.0205 & -0.0168 & -0.0250 \\
\hline
\end{tabular}




\begin{tabular}{llll}
\hline \multicolumn{1}{c}{ Area/Population } & $-1.5516^{*}$ & $-1.3985^{*}$ & $-1.2614^{*}$ \\
\hline LnPIB_percapita & 0.0109 & 0.0104 & 0.0115 \\
\hline Lnpopulação & $-0.0948^{*}$ & $-0.0893^{*}$ & -0.0781 \\
\hline Akaike & & 20171.55 & 20254.84 \\
\hline
\end{tabular}

Source: Prepared by the authors.

Note: Values succeeded by $(*)$ represent statistical significance $5 \%$ level.

Note: Prec $=$ precipitation $(\mathrm{mm}) ;$ temp $=$ temperature $\left({ }^{\circ} \mathrm{c}\right) ; d v=$ standard deviation.

One of the advantages of estimating the spatial lag model is the possibility of quantifying spatial overflow through direct. Indirect and total marginal effects (Note 13). The results for this procedure are presented in the appendix in Table 7. The averages for the marginal effects of the quadratic variables are outlined in Table 4.

The average direct effects of the squares of the precipitation levels indicate that an increase in precipitation of a given municipality in $1 \mathrm{~mm}$ during the autumn season reduces the value of the agricultural production of that municipality by approximately $0.0155 \%$. The indirect marginal effects of this variable indicate that the increase of 1 $\mathrm{mm}$ in the average autumn rainfall in a given municipality reduces by approximately $0.0038 \%$ the value of the agricultural production of neighboring municipalities. The overall impact of the $1 \mathrm{~mm}$ increase in the average temperature in the fall is a reduction of $0.0194 \%$ in the value of agricultural production.

Regarding the squares of the temperatures by seasons, the direct effects show that the increase of $1 \mathrm{~mm}$ in the average autumn and winter temperatures of a given municipality reduces by $0.4523 \%$ and increases by $0.1307 \%$, respectively. The value of agricultural production in that municipality. On the other hand, the indirect effects indicate that the increase of $1{ }^{\circ} \mathrm{C}$ in the temperature of autumn and winter in a certain municipality overflows spatially, reducing by $0.1127 \%$ and $0.0325 \%$ the value of the agricultural production of the neighboring municipalities. Also, the total effects indicate that the $1{ }^{\circ} \mathrm{C}$ increase in autumn and winter temperatures in municipality $i$ reduces by $0.5664 \%$ and increases by $0.1631 \%$, respectively, the value of the agricultural production in that municipality and in the neighboring municipalities.

Table 4. Average marginal effects for climatic variables by season

\begin{tabular}{llll}
\hline & Direct & Indirect & Total \\
\hline Prec_autumn $^{2}$ & -0.0155 & -0.0038 & -0.0194 \\
\hline Temp_autumn $^{2}$ & -0.4523 & -0.1127 & -0.5664 \\
\hline Temp_winter $^{2}$ & 0.1307 & 0.0325 & 0.1631 \\
\hline
\end{tabular}

Source: Prepared by the authors

Continuing the analysis of the marginal effects of the fixed-effects model with spatial lags, it can be observed that the values of the direct effects for the quadratic temperature in the autumn and winter seasons and the deviations of the temperature in autumn and the precipitation in spring differ from the value of their respective coefficients in the estimation described in Table 3. According to Lesage and Pace (2009), this difference occurs as a result of the so-called feedback effect, which denotes changes in the value of agricultural production, which overflow in spatial terms and with the passage of time returns to the municipality of origin.

Regarding the deviations of temperatures per season, the direct effects indicate that the increase of $1{ }^{\circ} \mathrm{C}$ in the fall temperature in relation to the annual average temperature causes a local elevation of $0.3432 \%$ in agricultural production. On the other hand, the indirect effects indicate that the increase of $1{ }^{\circ} \mathrm{C}$ in the temperature of autumn in relation to the average annual temperature of a given municipality increases by $0.0853 \%$ the agricultural production of its neighbors. The total effects indicate that the overall impact of this change is $0.4285 \%$ on the value of agricultural production.

The direct marginal effects of seasonal precipitation deviations indicate that a $1 \mathrm{~mm}$ rise in the distance between the average precipitation in the spring and the average annual precipitation of a municipality reduces its agricultural 
production by $0.0259 \%$, and in $0.0064 \%$ the production of neighboring municipalities, respectively. The total effects show that the overall impact of this change, considering the specific municipality and its neighbors, is a reduction of $0.0323 \%$ in the value of agricultural production.

The impacts of temperature and precipitation on agricultural production can only be visualized by calculating the sensitivities as denoted in Equation 11. This procedure is demonstrated in terms of averages for the Northeast region of Brazil in Figure 1.

From 2006 to 2011, agricultural production in the Brazilian Northeast was more sensitive to changes in temperature levels than to changes in average precipitation. From that point on, agricultural production became more sensitive to changes in precipitation levels, with the exception of 2014. Also, comparing the year 2016 with the beginning of the analyzed period, agricultural production in the Northeast region became more sensitive to changes in precipitation levels and less sensitive to changes in temperature.

The trajectory of the sensitivities outlined in Figure 1 demonstrates an already expected and well-known conclusion, which indicates a great dependence of the agricultural sector on rainfall stability and that public policies to mitigate the effects of climate change on agriculture in the Brazilian Northeast region will have greater impacts when based on hydric soil characteristics.

The high levels of sensitivity of the Northeastern agricultural production to climate change, as well as the intensification of the average sensitivity to the changes in pluviometry described in Figure 1, expose producers to a situation already verified by Burke and Emerick (2016), which indicate that farmers need adaptation to the new climate scenarios, mainly with respect to technology and other factors that influence agricultural productivity.

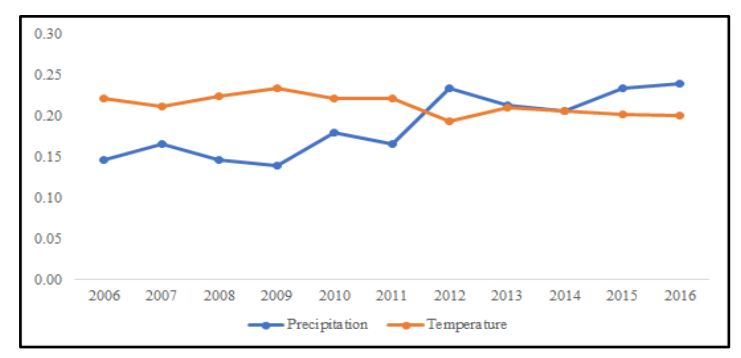

Figure 1. Average sensitivity of agricultural production in relation to precipitation and temperature Source: Prepared by the authors using the research data.

The intensification of agricultural production sensitivity in relation to changes in average precipitation levels from 2014 can be explained mainly by the worsening water scarcity that has been installed in most of the municipalities of the Brazilian Northeast in this period, as shown by the World Bank document organized by De Nys et al (2016).

Thus, it can be stated that the control of temperature shifts is an important mechanism for the adequate performance of agricultural production in the Brazilian Northeast. However, as stated by Machado Filho et al. (2016), climate-friendly policies for the agricultural sector will produce greater impacts if they are based on the control and efficient use of local water resources.

Table 5 shows the mean sensitivities for the Brazilian Northeast and the states of the region. It is verified that. on average. the increase of $1 \mathrm{~mm}$ in the level of annual rainfall increases the value of agricultural production in the Northeast by $0.1874 \%$, while the increase of $1{ }^{\circ} \mathrm{C}$ in the average annual temperature raises agricultural production by $0.2129 \%$ in the region.

Furthermore, it is possible to observe that Ceará was the state that showed the greatest average sensitivity in relation to changes in annual precipitation, followed by the states of Rio Grande do Norte and Paraíba. In relation to temperature, the highest average sensitivity was obtained by the state of Maranhão, followed by the states of Piauí and Ceará.

Considering the averages, only the states of Bahia and Maranhão show sensitivity levels to rainfall changes lower than the values obtained by the Northeast region as a whole. Regarding temperature, this behavior was observed for the states of Alagoas, Bahia, Ceará, Paraíba, Pernambuco, Rio Grande do Norte and Sergipe. 
Table 5. Average state sensitivity

\begin{tabular}{lll}
\hline State & Precipitation & Temperature \\
\hline Northeast & 0.1874 & 0.2129 \\
\hline Alagoas & 0.2080 & 0.1937 \\
\hline Bahia & 0.1814 & 0.2063 \\
\hline Ceará & 0.2129 & 0.2120 \\
\hline Maranhão & 0.1330 & 0.2382 \\
\hline Paraíba & 0.2098 & 0.2102 \\
\hline Pernambuco & 0.2061 & 0.2041 \\
\hline Piauí & 0.1975 & 0.2208 \\
\hline Rio Grande do Norte & 0.2104 & 0.2070 \\
\hline Sergipe & 0.1890 & 0.1963 \\
\hline
\end{tabular}

Source: Prepared by the authors.

Table 6 features a more detailed description of the average sensitivities of precipitation and temperature, presenting values per year for each Brazilian state in the region. Regarding the average sensitivities for precipitation, Table 6 shows that all the states in the region presented sensitivity growth in the year 2016, when compared to the initial year of the sample. It should be noted that the sensitivity of the agricultural sector to rainfall changes has already been verified for other localities, as discussed by Kunwar and Bohara (2017), which analyzed Nepal, and Baylis et al. (2011), which studied the United States of America.

Specifically, between 2006 and 2009, the state of Pernambuco was more sensitive to rainfall changes. In 2011, this characteristic was observed for the state of Sergipe, and from 2010 onwards, the greatest sensitivities to rainfall changes were observed in the state of Rio Grande do Norte.

Regarding the average sensitivity to shifts in temperature, it is verified that all the states in the region had their sensitivities decreased, when comparing the values of 2016 with the initial year of sample.

The greatest sensitivities were obtained by the State of Maranhão, from 2006 to 2016. This result is consistent with expectations, considering the geographic location of the state to the Northwest of the region, and its proximity to the Northern region of Brazil. Furthermore, according to INPE (2015), the annual rainfall level of Maranhão makes it stand out, presenting a tendency that differentiates it from other states regarding temperature effects.

Table 6. Average Sensitivity per year and state

\begin{tabular}{|c|c|c|c|c|c|c|c|c|c|}
\hline \multicolumn{10}{|c|}{ Precipitation } \\
\hline & $\mathrm{AL}$ & $\mathrm{BA}$ & $\mathrm{CE}$ & MA & PB & $\mathrm{PE}$ & PI & RN & SE \\
\hline 2006 & 0.2008 & 0.1503 & 0.1200 & 0.1037 & 0.1923 & 0.2051 & 01536 & 0.0716 & 0.1204 \\
\hline 2007 & 0.1507 & 0.1646 & 0.1650 & 0.1254 & 0.2082 & 0.2091 & 0.1967 & 0.1283 & 0.0377 \\
\hline 2008 & 0.1612 & 0.1637 & 0.1399 & 0.0876 & 0.1628 & 0.1757 & 0.1576 & 0.1253 & 0.0958 \\
\hline 2009 & 0.1591 & 0.1600 & 0.1325 & 0.0786 & 0.1512 & 0.1736 & 0.1370 & 0.1034 & 0.1208 \\
\hline 2010 & 0.1881 & 0.1665 & 0.2407 & 0.1390 & 0.2094 & 0.1844 & 0.2001 & 0.2544 & 0.1967 \\
\hline 2011 & 0.2022 & 0.1748 & 0.1720 & 0.0866 & 0.1635 & 0.1781 & 0.1722 & 0.1866 & 0.2227 \\
\hline 2012 & 0.2498 & 0.2082 & 0.2775 & 0.1822 & 0.2660 & 0.2453 & 0.2393 & 0.3043 & 0.2578 \\
\hline 2013 & 0.2320 & 0.1960 & 0.2693 & 0.1419 & 0.2336 & 0.2193 & 0.2082 & 0.2878 & 0.2475 \\
\hline 2014 & 0.2299 & 0.1890 & 0.2551 & 0.1307 & 0.2291 & 0.2103 & 0.2106 & 0.2722 & 0.2436 \\
\hline 2015 & 0.2596 & 0.2109 & 0.2737 & 0.1809 & 0.2521 & 0.2334 & 0.2437 & 0.2936 & 0.2710 \\
\hline
\end{tabular}




\begin{tabular}{llllllllll}
\hline 2016 & 0.2542 & 0.2117 & 0.2965 & 0.2069 & 0.2394 & 0.2330 & 0.2538 & 0.2872 & 0.2650 \\
\hline \multicolumn{2}{l}{ Temperature } & & & & & & & & \\
\hline 2006 & 0.1916 & 0.2186 & 0.2203 & 0.2483 & 0.2097 & 0.2045 & 0.2331 & 0.2079 & 0.1901 \\
\hline 2007 & 0.1890 & 0.2064 & 0.2103 & 0.2411 & 0.2057 & 0.1967 & 0.2159 & 0.2044 & 0.1974 \\
\hline 2008 & 0.2057 & 0.2084 & 0.2323 & 0.2516 & 0.2288 & 0.2204 & 0.2303 & 0.2281 & 0.1982 \\
\hline 2009 & 0.2160 & 0.2227 & 0.2424 & 0.2538 & 0.2322 & 0.2256 & 0.2358 & 0.2387 & 0.2204 \\
\hline 2010 & 0.2178 & 0.2218 & 0.2097 & 0.2367 & 0.2159 & 0.2225 & 0.2236 & 0.2054 & 0.2147 \\
\hline 2011 & 0.2043 & 0.2064 & 0.2298 & 0.2357 & 0.2329 & 0.2194 & 0.2269 & 0.2291 & 0.1950 \\
\hline 2012 & 0.1669 & 0.1877 & 0.1910 & 0.2296 & 0.1832 & 0.1756 & 0.2074 & 0.1823 & 0.1695 \\
\hline 2013 & 0.1803 & 0.2073 & 0.1983 & 0.2350 & 0.2037 & 0.1991 & 0.2211 & 0.1935 & 0.1864 \\
\hline 2014 & 0.1850 & 0.1999 & 0.2040 & 0.2355 & 0.1999 & 0.1943 & 0.2155 & 0.1997 & 0.1834 \\
\hline 2015 & 0.1824 & 0.1962 & 0.2014 & 0.2296 & 0.1955 & 0.1929 & 0.2109 & 0.1932 & 0.1788 \\
\hline 2016 & 0.1818 & 0.1935 & 0.1923 & 0.2229 & 0.2045 & 0.1943 & 0.2083 & 0.1950 & 0.1814 \\
\hline
\end{tabular}

Source: Prepared by the authors.

In general, the results presented in Table 6 indicate that agricultural production in the Northeast region has become increasingly sensitive to variations in the precipitation levels, while changes in average temperatures have influenced to a lesser extent the value of agricultural production.

Historically, agricultural production in the Northeast region of Brazil has suffered from a lack of policies aimed at solving the problems arising from the region's water shortages, such as the application of measures to encourage the efficient use of water resources in farming. Also, these results indicate that public policies to mitigate the effects of climate change on agriculture in the Northeast region of Brazil will have greater impacts when based on the water needs of this region's municipalities.

Thus, it can be said that agriculture in the municipalities of the Northeast region of Brazil has suffered from a lack of policies aimed at solving the problems stemming from the water scarcity of the region. Also, the need to apply incentive measures to the efficient use of water resources in agriculture can be highlighted.

Results from the present work indicate the need for implementation of public policies that seek to reduce the effects of climate change on agriculture in the region analyzed. Some suggestions of public policies would be: (i) Policies aimed at adapting agricultural farmers to climate change; (ii) Policies that view or use appropriate local water resources; (iii) Technical qualification for agricultural producers to adapt to changes in the local climate, and; (iv) Measures aimed at reducing climate change, such as controlling greenhouse gas emissions and deforestation monitoring.

Furthermore, this work also shows evidence which suggests the need to intensify some existing policies in the region, such as the technical assistance given to farmers by the Technical Assistance Company of State of Ceará (Empresa de Assistência Técnica do Estado do Ceará - EMATERCE), Brazil, such as technical irrigation techniques, with the objective of minimizing inefficiency in the use of water resources, as well as providing assistance to enable local producers to grow climate-adapted crops.

\section{Concluding Remarks}

The present work had as its objective to verify the sensitivity of the agricultural production in the Northeast region of Brazil in relation to changes in precipitation and temperature levels. For that purpose, climate data was used, organized in terms of time period and geography, and the sensitivities were estimated by means of an econometric procedure for spatial panel data. i.e., the adopted econometric procedure includes the effects of the spatial proximity of the data units. Mean precipitation and temperature data were used for a set of municipalities in the Northeast region of Brazil between 2006 and 2016.

The results showed that the agricultural production of the municipalities of the Brazilian Northeast is spatially autocorrelated over the years analyzed. The existence of spatial agglomerations of agricultural production in the 
Northeastern municipalities was verified through the calculation of the Moran Global Index, indicating that there are municipalities with high (or low) levels of production, which have neighbors with these same characteristics.

Through the estimation of a spatial lag model, it was observed that changes in the production of a given municipality overflow spatially, also impacting the neighboring municipalities. Thus, public policies to support the agricultural sector of the Northeastern municipalities should be applied at a regional, and not just municipal, level, allowing greater efficiency.

With the calculation of the sensitivities, it was also verified that from 2006 to 2011, the agricultural production of the Brazilian Northeast was more sensitive to changes in temperature levels than to changes in average precipitation. However, after the years 2012, 2013, 2015 and 2016, agricultural production has become more sensitive to changes in the precipitation levels.

It was also noted that in the analyzed period there was an increase in the average sensitivity of the agricultural production in relation to the precipitation levels, while the average temperature sensitivity showed a decrease. In addition, it was verified that, on average, the agricultural production of the states of Pernambuco, Sergipe and Rio Grande do Norte present the greatest sensitivities to rainfall changes, while agriculture in the state of Maranhão is the most sensitive to changes in temperature levels.

Lastly, it can be concluded that the agricultural production in the Northeast region of Brazil has featured a lack of policies aimed at solving the problems arising from the region's water shortages, such as the application of measures to encourage the efficient use of water resources in farming. Furthermore, this work surmises that public policies to mitigate the effects of climate change on agriculture in the Northeast region of Brazil will have greater impacts when based on the water needs of this region's municipalities.

\section{References}

Almeida, E. S. (2012). Econometria espacial aplicada. Campinas, São Paulo, Editora Alínea.

Almeida, E. S., Perobelli, F. S., \& Ferreira, P. G. C. (2008). Existe convergência espacial da produtividade agrícola no Brasil?. Rev. Econ. Sociol. Rural, 46(1).

Anselin, L. (1999). Interactive techniques and exploratory spatial data analysis. In P. A. Longley (Ed.), Geographic information system: principles, techniques, management and applications. Nova York.

Araújo, P. H. C., Silva, F. F., Gomes, M. F. M., Féres, J. G., \& Braga, M. J. (2014). Uma análise do impacto das mudanças climáticas na produtividade agrícola da região Nordeste do Brasil. Revista Econômica do Nordeste, 45(3), 46-57.

Barreto, R. C., Almeida, E. S., \& Lima, J. E. (2010). Convergência espacial do PIB per capita no estado do Ceará. Revista de Economia, 36(3), 25-40.

Baumont, C. (2004). Spatial effects in housing price models: Do housing prices capitalize urban development policies in the agglomeration of Dijon. Document de travail - Economie 2004-04. LEG -Laboratoire d'Economie et de Gestion. CNRS UMR 5118. Université de Bourgogne.

Baylis, K., Paulson, N. D., \& Piras, G. (2011). Spatial approaches to panel data in agricultural economics: A climate change application. Journal of Agricultural and Applied Economics, 43(3), 325-338.

Bueno, L. R. S. (2008). Econometria de séries temporais. São Paulo: Cengage Learning.

Burke, M., \& Emerick, K. (2016). Adaptation to climate change: Evidence from US agriculture. American Economic Journal: Economic Policy, 8(3), 106-140.

Calzadilla, A., Rehdanz, K., Betts, R., Falloon, P., Wiltshire, A., \& Tol, R. S. (2013). Climate change impacts on global agriculture. Climatic Change, 120(1-2), 357-374.

Cancian, V., Vidigal, V. G., \& Vidigal, C. B. R. (2013). Pobreza e desigualdade de renda nos municípios da região sul do Brasil: uma análise espacial. XVI Encontro de Economia da Região Sul. Anais.

Cunha, D. A., Coelho, A. B., Féres, J. G., Braga, M. J., \& Souza, E. C. (2013). Irrigação como estratégia de adaptação de pequenos agricultores às mudanças climáticas: aspectos econômicos. Revista de Economia e Sociologia Rural, 51(2), 369-386.

Dayaratna, K. D., Mckitrick, R., \& Michaels, P. J. (2020). Climate sensitivity, agricultural productivity and the social cost of carbon in FUND. Environmental Economics and Policy Studies, 22, 433-448. https://doi.org/10.1007/s10018-020-00263-w 
De Nys, E., Engle, N. L., \& Magalhães, A. R. (2016). Secas no Brasil: política e gestão proativas. Centro de Gestão de Estudos Estratégicos. Banco Mundial.

Domingues, E. P., Magalhães, E. S., \& Ruiz, R. M. (2011). Cenários de mudanças climáticas e agricultura no Brasil: Impactos econômicos na Região Nordeste. Revista Econômica do Nordeste, 42(2).

Elhorst, J. P. (2003). Specification and estimation of spatial panel data models. International Regional Sciences Review, 26(3), 244-268.

Evangelista, P., Young, N., \& Burnett, J. (2013). How will climate change spatially affect agriculture production in Ethiopia? Case studies of important cereal crops. Climatic Change, 119(3-4), 855-873.

FAO (Food And Agriculture Organization of the United Nations). (2009). Climate change: impacts on agriculture and costs of adaptation. Washington. D.C. Retrieved from http://www.fao.org/fileadmin/user_upload/rome2007/docs/Impact_on_Agriculture_and_Costs_of_Adaptation.p df

Fischer, G., Shah, M. M., \& Van Velthuizen, H. T. (2002). Climate change and agricultural vulnerability. Special Report International Institute for Applied System Analysis (IIASA), Laxenburg, Austria. Retrieved from http://adapts.nl/perch/resources/climateagri.pdf

Gonçalves, E. (2007). O padrão espacial da atividade inovadora Brasileira: uma análise exploratória. Estudos Econômicos, 37(2).

INPE (Instituto Nacional de Pesquisas Espaciais). (2015). Cenários de mudanças climáticas: Regionalização. Retrieved from http://mudancasclimaticas.cptec.inpe.br/ rmclima/pdfs/prod_probio/Relatorio_3.pdf

Ju, H., Van, D. E. R., Velde, M., Lin, E., Xiong, W., \& Li, Y. (2013). The impacts of climate change on agricultural production systems in China. Climatic Change, 324, 120-313.

Kunwar, S. B., \& Bohara, A. K. (2017). Climate sensitivities and farmland values in Nepal: A spatial panel Ricardian approach. Journal of Development and Agricultural Economics, 9(6), 145-161.

Lesage, J. P., \& Pace, R. K. (2009). Introduction to spatial econometrics. London: CRC Press.

Machado Filho, H., Moraes, C., Bennati, P., Rodrigues, R. A., Guilles, M., Rocha, P., ... Vasconcelos, A. L. I. (2016). Mudanças no clima e os impactos na agricultura familiar no Norte e Nordeste do Brasil. Estratégia do FIDA para o Brasil 2016-2021 e série de estudos sobre a pobreza rural.

Moraes, G. I., \& Ferreira Filho, J. B. S. (2013). Brasil: mudanças climáticas e economia: o que há estabelecido?. Planejamento e Políticas Públicas (PPP), (41).

Nunes, C. R. P. (2016). As mudanças climáticas a partir da implantação de empresas de capital estrangeiro no nordeste: estado regulador?. In Os impactos das mudanças climáticas no nordeste brasileiro. Fundação SINTAF.

Obermaier, M., \& Rosa, L. P. (2013). Mudança climática e adaptação no Brasil: uma análise crítica. Estudos Avançados, 27(78), 155-176.

Ochieng, J., Kirimi, L., \& Mathenge, M. (2016). Effects of climate change on agricultural production: the case of small scale farmers in Kenya. NJAS -Wageningen Journal of Life Sciences, 203.

Oo, A. T., Van Huylenbroeck, G., \& Speelman, S. (2020). Measuring the economic impact of climate change on crop production in the dry zone of myanmar: a ricardian approach. Climate, (8). https://doi.org/10.3390/cli8010009

Ortiz-Bobea, A., Knippenberg, E., \& Chambers, R. G. (2018). Growing climatic sensitivity of U.S. agriculture linked to technological change and regional specialization. Science Advances, 12. https://doi.org/10.1126/sciadv.aat4343

Parry, M. L., Rosenzweig, C., Iglesias, A., Livermore, M., \& Fischer, G. (2004). Effects of climate change on global food production under SRES emissions and socio-economic scenarios. Global Environmental Change, 14(1), 53-67.

Piao, S., Ciais, P., Huang, Y., Shen, Z., Peng, S., Li, J., \& Friedlingstein, P. (2010). The impacts of climate change on water resources and agriculture in China. Nature, 467(7311), 43-51. 
Rosegrant, M. W., Ewing, M., Yohe, G., Burton, I., Huq, S., \& Valmonte-Santos, R. (2008). Clinate change and agriculture. Deutsche Gesellschaft fur. Eschborn.

Schleussner, C. F., Deryng, D., Muller, C., Elliott, J., Saeed, F., Folberth, C., ... Rogelj, J. (2018). Crop productivity changes in $1.5^{\circ} \mathrm{C}$ and $2{ }^{\circ} \mathrm{C}$ worlds under climate sensitivity uncertainty. Environmental Research Letters, 13.

Shi, Z., Huang, H., Wu, Y., Chiu, Y. H., \& Qin, S. (2020). Climate Change Impacts on Agricultural Production and Crop Disaster Area in China. International Journal of Environmental Research and Public Health, 17, 4792. https://doi.org/10.3390/ijerph17134792

Wiebe, K., Lotze-Campen, H., Sands, R., Tabeau, A., Van Der Mensbrugghe, D., Biewald, A., ... Müller, C. (2015). Climate change impacts on agriculture in 2050 under a range of plausible socioeconomic and emissions scenarios. Environmental Research Letters, 10(8).

Yalew, A. W., George, H., Herman, L. C., \& Stefan, T. (2017). Economic effects of climate change in developing countries: Economy-wide and regional analysis for Ethiopia. CEPIE Working Paper, n. 10.

\section{Notes}

Note 1. According to the Ministério do Meio Ambiente (MMA) - Brazilian Ministry of Environment. Available at: http://www.mma.gov.br/clima/convencao-das-nacoes-unidas/acordo-de-paris . Last accessed: April 17th, 2019.

Note 2. Available at https://data.giss.nasa.gov/gistemp/graphs_v3/. Last Accessed: April 17th, 2019.

Note 3. It should be noted that in much of the Brazilian Northeast, climate seasons are not temporally well defined as specified, however, given the great variability in the definition of the seasons, and the lack of concrete information about the time in which these seasons occur in each municipality of the region, the authors decided to consider the period of the four conventional climate seasons as defined by INPE.

Note 4. The other municipalities were disregarded in view of the lack of information on climate variables or the value of agricultural production.

Note 5. Considering $\mathrm{y}$ as the value of rural establishments and $\mathrm{X}$ as the explanatory variables. Kunwar and Bohara (2017) consider a model such that $y=f\left(X . X^{2} . X_{d v}\right)$.. However, considering the problem of collinearity with the data used, the climate variables by season were only approached in the present work in its quadratic form.

Note 6. These variables were chosen based on various works in the literature, such as Baylis et al. (2011) and Kunwar and Bohara (2017).

Note 7. Made available annually by the IBGE. In view of the non-availability of this information for the year 2016, an estimate was considered, which was reached by multiplying the growth rate of the GDPs of 2014 and 2015 with the GDP of 2015.

Note 8. Baylis et al. (2011) use population density. However, considering the collinearity problem of this variable with the data used here, it was decided to use the average area per inhabitant, given by Area (municipal) / Population. Note 9. Population estimates made available by the IBGE were used.

Note 10. Annual and seasonal averages of daily values of temperature and precipitation were used, that is: $E\left(\right.$ temp $_{t} \cdot$ prec $\left._{t}\right)=\sum(\text { temp. prec })_{\text {day }} / \sum$ days

Note 11. For the construction of the deviations, the difference between the daily average of the stations and the annual daily average was used.

Note 12. The results for this procedure are described in the appendix. Table 8.

Note 13. Since the variables by season of the year are squared. the marginal effects for these variables were calculated considering Effect (prec.temp $)_{\text {season }}=2 * \sigma_{\text {effect }} *(\text { prec. temp })_{\text {season }}$. 


\section{Appendix}

Table 1. Direct, indirect and total marginal effects of the spatial lag model

\begin{tabular}{|c|c|c|c|}
\hline & Direct & Indirect & Total \\
\hline Precipitation & $-0.5979 *$ & $-0.1484 *$ & $-0.7462 *$ \\
\hline Temperature & $0.1526^{*}$ & $0.0379^{*}$ & $0.1904 *$ \\
\hline Precipitation $^{2}$ & $0.0210^{*}$ & $0.0052^{*}$ & $0.0262 * *$ \\
\hline Temperature $^{2}$ & 0.0029 & 0.0007 & 0.0037 \\
\hline prec $*$ temp & $0.0341 *$ & $0.0085^{*}$ & $0.0426^{*}$ \\
\hline$(p r e c * \text { temp })^{2}$ & $-0.0001^{*}$ & $-0.0001^{*}$ & $-0.0001^{*}$ \\
\hline Prec_spring ${ }^{2}$ & -0.0008 & -0.0002 & -0.0010 \\
\hline Prec_summer $^{2}$ & -0.0008 & -0.0002 & -0.0010 \\
\hline Prec_autumn ${ }^{2}$ & $-0.0019 *$ & $-0.0005^{*}$ & $-0.0023^{*}$ \\
\hline Prec_winter $^{2}$ & -0.0007 & -0.0002 & -0.0009 \\
\hline Temp_spring ${ }^{2}$ & -0.0007 & -0.0002 & -0.0008 \\
\hline Temp_summer ${ }^{2}$ & -0.0013 & -0.0003 & -0.0016 \\
\hline Temp_autumn ${ }^{2}$ & $-0.0090 *$ & $-0.0022^{*}$ & $-0.0112^{*}$ \\
\hline Temp_winter ${ }^{2}$ & $0.0027^{*}$ & $0.0007^{*}$ & $0.0034^{*}$ \\
\hline Temp_spring_dv & 0.0687 & 0.0170 & 0.0857 \\
\hline Temp_summer_dv & 0.0520 & 0.0129 & 0.0649 \\
\hline Temp_autumn_dv & 0.3432 & $0.0853^{*}$ & $0.4285^{*}$ \\
\hline Temp_winter_dv & -0.0930 & -0.0231 & -0.1161 \\
\hline Prec_winter_dv & $-0.0259 *$ & $-0.0064 *$ & $-0.0323^{*}$ \\
\hline Prec_summer_dv & 0.0174 & 0.0043 & 0.0217 \\
\hline Prec_autumn_dv & 0.0211 & 0.0052 & 0.0263 \\
\hline Prec_winter_dv & -0.0167 & -0.0041 & -0.0208 \\
\hline \multicolumn{4}{|l|}{ Control } \\
\hline Area/Population & $-1.4511^{*}$ & $-0.3606^{*}$ & $-1.8117 *$ \\
\hline LnGDP_percapita & 0.0102 & 0.0025 & 0.0127 \\
\hline Lnpopulation & $-0.0941^{*}$ & $-0.0233^{*}$ & $-0.1175^{*}$ \\
\hline
\end{tabular}

Source: Prepared by the authors.

Note: Values followed by $(*)$ represent statistical significance at the $5 \%$ confidence level.

Note: $\operatorname{Prec}=$ precipitation $(\mathrm{mm}) ;$ temp $=$ temperature $\left({ }^{\circ} \mathrm{c}\right) ; d v=$ standard deviation.

Table 2. Spatial autocorrelation of model residuals without spatial specification

\begin{tabular}{llllllllll}
\hline & Queen & Rook & $\mathrm{K}=1$ & $\mathrm{~K}=2$ & $\mathrm{~K}=3$ & $\mathrm{~K}=4$ & $\mathrm{~K}=5$ & $\mathrm{~K}=10$ & Dist. Fixa \\
\hline 2006 & $0.637^{*}$ & $0.637^{*}$ & $0.672^{*}$ & $0.667^{*}$ & $0.663^{*}$ & $0.651^{*}$ & $0.645^{*}$ & $0.612^{*}$ & $0.572^{*}$ \\
\hline 2007 & $0.683^{*}$ & $0.683^{*}$ & $0.709^{*}$ & $0.694^{*}$ & $0.698^{*}$ & $0.691^{*}$ & $0.685^{*}$ & $0.655^{*}$ & $0.607^{*}$ \\
\hline 2008 & $0.724^{*}$ & $0.724^{*}$ & $0.728^{*}$ & $0.728^{*}$ & $0.733^{*}$ & $0.732^{*}$ & $0.729^{*}$ & $0.708^{*}$ & $0.673^{*}$ \\
\hline 2009 & $0.647^{*}$ & $0.647^{*}$ & $0.669^{*}$ & $0.675^{*}$ & $0.672^{*}$ & $0.663^{*}$ & $0.658^{*}$ & $0.630^{*}$ & $0.595^{*}$ \\
\hline 2010 & $0.644^{*}$ & $0.644^{*}$ & $0.686^{*}$ & $0.665^{*}$ & $0.664^{*}$ & $0.661^{*}$ & $0.651^{*}$ & $0.616^{*}$ & $0.564^{*}$ \\
\hline 2011 & $0.786^{*}$ & $0.786^{*}$ & $0.798^{*}$ & $0.787^{*}$ & $0.790^{*}$ & $0.789^{*}$ & $0.786^{*}$ & $0.774^{*}$ & $0.755^{*}$ \\
\hline 2012 & $0.752^{*}$ & $0.752^{*}$ & $0.785^{*}$ & $0.786^{*}$ & $0.772^{*}$ & $0.769^{*}$ & $0.768^{*}$ & $0.741^{*}$ & $0.692^{*}$ \\
\hline 2013 & $0.745^{*}$ & $0.745^{*}$ & $0.772^{*}$ & $0.770^{*}$ & $0.767^{*}$ & $0.766^{*}$ & $0.763^{*}$ & $0.734^{*}$ & $0.690^{*}$ \\
\hline
\end{tabular}




\begin{tabular}{|c|c|c|c|c|c|c|c|c|c|}
\hline 2014 & $0.783 *$ & $0.783 *$ & $0.803^{*}$ & $0.800 *$ & $0.801 *$ & $0.802 *$ & $0.800^{*}$ & $0.781 *$ & $0.744 *$ \\
\hline 2015 & $0.763 *$ & $0.763 *$ & $0.796 *$ & $0.795^{*}$ & $0.787 *$ & $0.784 *$ & $0.781 *$ & $0.760 *$ & $0.726^{*}$ \\
\hline 2016 & $0.694 *$ & $0.694 *$ & $0.744^{*}$ & $0.738 *$ & $0.733 *$ & $0.721 *$ & $0.712 *$ & $0.676^{*}$ & $0.625^{*}$ \\
\hline
\end{tabular}

Source: Prepared by the authors.

Note: Values followed by $(*)$ represent statistical significance at the $5 \%$ confidence level.

Table 3. Results of the unit root test of the variables used

\begin{tabular}{|c|c|c|c|}
\hline Variable & $T$ & Adjusted-T & $P$ - Value \\
\hline Ln(Production) & -53.2822 & -25.3216 & 0.0000 \\
\hline Precipitation & -52.6171 & -20.9565 & 0.0000 \\
\hline Temperature & -67.2431 & -50.6413 & 0.0000 \\
\hline Precipitation $^{2}$ & -56.0657 & -24.6393 & 0.0000 \\
\hline Temperature $^{2}$ & -59.3222 & -41.9783 & 0.0000 \\
\hline prec $*$ temp & -62.1210 & -29.2593 & 0.0000 \\
\hline$(\text { prec } * \text { temp })^{2}$ & -63.8629 & -31.3029 & 0.0000 \\
\hline Prec_spring $^{2}$ & -87.8365 & -49.5635 & 0.0000 \\
\hline Prec_summer $^{2}$ & -92.1737 & -64.9030 & 0.0000 \\
\hline Prec_autumn $^{2}$ & -63.4509 & -30.9688 & 0.0000 \\
\hline Prec_winter $^{2}$ & $-6.3 e+06$ & $-6.9 e+06$ & 0.0000 \\
\hline Temp_spring ${ }^{2}$ & -51.5561 & -30.3136 & 0.0000 \\
\hline Temp_summer ${ }^{2}$ & -70.0420 & -50.9698 & 0.0000 \\
\hline Temp_autumn ${ }^{2}$ & -71.0980 & -55.0664 & 0.0000 \\
\hline Temp_winter ${ }^{2}$ & -57.8152 & -38.9584 & 0.0000 \\
\hline Temp_spring_dv & -82.4184 & -40.2622 & 0.0000 \\
\hline Temp_summer_dv & -78.7967 & -51.8877 & 0.0000 \\
\hline Temp_autumn_dv & $-1.1 \mathrm{e}+02$ & -83.0920 & 0.0000 \\
\hline Temp_winter_dv & -86.4852 & -64.7441 & 0.0000 \\
\hline Prec_spring_dv & -64.6259 & -28.2030 & 0.0000 \\
\hline Prec_summer_dv & $-1.1 \mathrm{e}+02$ & -63.4006 & 0.0000 \\
\hline Prec_autumn_dv & -68.1829 & -33.8877 & 0.0000 \\
\hline Prec_spring_dv & -56.1262 & -26.7274 & 0.0000 \\
\hline \multicolumn{4}{|l|}{ Control } \\
\hline Area/Population & -61.9080 & -42.3726 & 0.0000 \\
\hline LnGDP_percapita & -47.0768 & -32.2584 & 0.0000 \\
\hline Lnpopulation & -61.7892 & -44.3105 & 0.0000 \\
\hline
\end{tabular}

Source: Prepared by the authors.

\section{Copyrights}

Copyright for this article is retained by the author(s), with first publication rights granted to the journal.

This is an open-access article distributed under the terms and conditions of the Creative Commons Attribution license (http://creativecommons.org/licenses/by/4.0/). 